\title{
Kinetic Analysis of Low-Rank Coal Pyrolysis by Model-Free and Model-Fitting Methods
}

\author{
Qiuli Zhang, ${ }^{1}$ Min Luo $\left(\mathbb{D}^{1},{ }^{1}\right.$ Long Yan, ${ }^{2}$ Aiwu Yang, ${ }^{3}$ and Xiangrong Hui ${ }^{1}$ \\ ${ }^{1}$ School of Chemistry and Chemical Engineering, Xi'an University of Architecture and Technology, Xi'an 710055, China \\ ${ }^{2}$ School of Chemistry and Chemical Engineering, Yulin University, Yulin 719000, China \\ ${ }^{3}$ Xi'an Boyan Instrument Analysis and Application Technology Co.Ltd., Xi'an 710016, China
}

Correspondence should be addressed to Min Luo; 717luomin@gmail.com

Received 5 June 2019; Accepted 9 September 2019; Published 11 November 2019

Academic Editor: João Paulo Leal

Copyright ( 2019 Qiuli Zhang et al. This is an open access article distributed under the Creative Commons Attribution License, which permits unrestricted use, distribution, and reproduction in any medium, provided the original work is properly cited.

Coal SJC, coal WJG, coal ZJM, and coal HCG were selected to investigate the pyrolysis kinetics of northern Shaanxi coals. TG and DSC experiments of four coals were carried out with a synchronous thermal analyzer at heating rates 5, 10, 15, and 20 C/min, respectively. The pyrolysis characteristics were described by thermogravimetric data, and the kinetic parameters were calculated by Flynn-Wall-Ozawa (FWO), Kissinger, general integration, and MacCallum-Tanner methods. The results show that coal SJC, coal ZJM, and coal HCG all conform to the reaction series equation, the thermal decomposition reaction rate is controlled by chemical reaction, and coal WJG conforms to Avrami-Erofeev equation. The activation energies of the four coals are $177.53 \mathrm{~kJ} / \mathrm{mol}$, $200.34 \mathrm{~kJ} / \mathrm{mol}, 158.59 \mathrm{~kJ} / \mathrm{mol}$, and $240.47 \mathrm{~kJ} / \mathrm{mol}$, respectively.

\section{Introduction}

Coal is the most important primary energy in China at present. The national characteristics such as "rich coal, less gas, and poor oil" determine that the main energy status of coal will not change in a long period of time [1]. The coal resources in northern Shaanxi are rich, and the coal has characteristics low ash, low sulfur, low phosphorus, and high calorific values. Furthermore, its pyrolysis products are ideal materials to replace oil and gas [2]. At the same time, pyrolysis, as the basis of coal thermal conversion (gasification, liquefaction, and oxidation) process, is the first step to develop new coal utilization technology [3]. At present, many studies on coal pyrolysis have been reported at home and abroad. The distributed activation energy model (DAEM) is the most common method to study the dynamic behavior of coal pyrolysis. It has been used to analyze the pyrolysis kinetics of typical long flame coal [4], Russian anthracite and Italian bituminous coal [5], Yunnan, Shandong, and Inner Mongolia coal [6], and Ningxia and Heilongjiang coal [7]. Based on the standard DAEM model, 2-DAEM and 3-DAEM are proposed. In recent years, the model-free method and model- fitting method have been applied to the kinetic analysis of the solid fuel pyrolysis process. The model-free method (i.e., isoconversion method) obtains relatively reliable apparent activation energy without involving the kinetic model function. By comparing the activation energy values of different conversion rates, the consistency of the reaction mechanism of the whole pyrolysis process is verified. The model-fitting method is a method that combines the experimental data with the dynamic model. The model-free methods include the Flynn-Wall-Ozawa (FWO) method, Kissinger method, Starink method, and Friedman method. The Coats-Redfern method, MacCallum-Tanner method, general integration methodm and some others are model-fitting methods. Shi et al. [8] used the FWO, Kissinger, and FR methods to analyze the kinetic characteristics of combustion of moso bamboo and hydrothermal charcoal. The activation energies of the FWO and Kissinger methods were similar. Wang et al. [9] discussed the thermal degradation behavior of nano- $\mathrm{CaCO}_{3}, \mathrm{BPF}$, epoxy resin, and IMBPF/epoxy resin composites in nitrogen atmosphere. The average activation energy of IMBPF/epoxy resin composites obtained by FWO and Vyazovkin and Weight (VW) methods was higher than that of the 
unmodified BPF. Furthermore, the value determined by the FWO method was better than that by the VW method. Peng et al. [10] used the Coats-Redfern method to calculate the global and main product kinetic parameters of coal pyrolysis based on flow-bed hot-carrier gas. It was found that higher initial temperature or velocity of gas heat carrier and smaller particle size or moving speed of coal could accelerate the rate of volatilization and shorten the pyrolysis time. Jain et al. [11] described the devolatilization kinetics of typical Indian coal by means of the model-free method and model-fitting method. Liu et al. [12] determined the pyrolysis kinetic parameters of Inner Mongolia superfine pulverized coal by Coats-Redfern, Starink, and Miura-Maki DAEM methods and found that the activation energies determined by the Starink method were more accurate.

However, there are few reports on the kinetics analysis of coal pyrolysis by the FWO method, Kissinger method, general integration method, and MacCallum-Tanner method. Meanwhile, there are few studies on coal in northern Shaanxi. Therefore, in this work, TG and DSC analysis experiments with different heating rates were carried out on coal samples from four different mining areas in northern Shaanxi. The kinetic parameters activation energy $E$ and pre-exponential factor $A$ of each coal sample pyrolysis process were calculated by the FWO method, Kissinger method, general integration method, and MacCallumTanner method, respectively. It will lay a foundation for the following kinetics analysis of gas product release and solid coke change in coal pyrolysis.

\section{Methods}

2.1. Materials. Four coals with distinctive coalification extent were collected from different mines in northern Shaanxi, China, denoted as Wang Jiagou (WJG), He Caogou (HCG), Sun Jiacha (SJC), and Zhang Jiamao (ZJM). The coal samples were arranged in accordance with increasing carbon content. In order to avoid the effect of mass and heat transfer on the pyrolysis process, the samples were pulverized and sieved into $<0.075 \mathrm{~mm}$ (200 mesh) of particle size used for TG-DSC experiment. The proximate and ultimate analyses of four coal samples are listed in Table 1 . It can be seen that coal WJG has the lowest volatile content (25.73 wt.\%) and the highest ash content (24.92 wt.\%). The volatile content of others was high in the range of 38.76-54.73 wt and the ash was low in the range of 1.04-5.00 wt.\%. The contents of carbon and hydrogen of all coal samples ranged from 78.16 to $83.27 \mathrm{wt}$ \% and from 3.87 to $5.42 \mathrm{wt} \%$, respectively.

2.2. TGA Experiment. The pyrolysis experiments were carried out in a simultaneous DSC-TGA (NETZSCH-STA 409) under high-purity $\mathrm{N}_{2}$ with a flow rate of $50 \mathrm{ml} / \mathrm{min}$. In each experiment, about $5 \mathrm{mg}$ coal samples were placed in a platinum crucible and heated at room temperature to $900^{\circ} \mathrm{C}$ at four different heating rates: 5, 10, 15 and $20^{\circ} \mathrm{C} / \mathrm{min}$. Each experiment was repeated at least three times to eliminate the vibration error.
TABLe 1: Proximate and ultimate analyses of coal samples.

\begin{tabular}{lcccc}
\hline Property & Coal & Coal & Coal & Coal \\
& SJC & WJG & ZJM & HCG \\
\hline Proximate analysis (wt.\%, ad) & & & & \\
Moisture & 6.22 & 4.74 & 6.71 & 2.58 \\
Volatiles & 52.83 & 25.73 & 54.73 & 38.76 \\
Fixed carbon & 35.95 & 44.61 & 36.66 & 57.62 \\
Ash & 5.00 & 24.92 & 1.90 & 1.04 \\
\hline Ultimate analysis (wt.\%, daf) & & & & \\
Carbon & 78.16 & 78.41 & 82.88 & 83.27 \\
Hydrogen & 5.33 & 3.87 & 5.42 & 5.41 \\
Oxygen & 14.94 & 15.55 & 10.08 & 8.78 \\
Nitrogen & 1.10 & 1.16 & 0.89 & 2.07 \\
Sulfur & 0.47 & 1.01 & 0.73 & 0.47 \\
\hline
\end{tabular}

2.3. Principle of Dynamics. The rate of solid-state chemical reaction is generally expressed as follows [13]:

$$
\frac{\mathrm{d} \alpha}{\mathrm{d} t}=k(T) f(\alpha)
$$

where $f(\alpha)$ is the differential mechanism function that is correlated to the extent of conversion $\alpha ; k(T)$ represents the temperature dependence of the rate constant which can be substituted with the Arrhenius equation; and $T=T_{0}+\beta t, T_{0}$ is the initial temperature, the heating rate $\beta$ is a constant, $t$ is the time.

Then, equation (1) is transformed into the following forms under nonisothermal conditions adopted in this work:

$$
\frac{\mathrm{d} \alpha}{\mathrm{d} T}=\frac{A}{\beta} f(\alpha) \exp \left(-\frac{E}{R T}\right)
$$

where $A$ and $E$ are kinetic parameters that represent the preexponential factor and activation energy, respectively. $R$ is referred to as the gas constant.

The integration of equation (2) is as follows:

$$
G(\alpha)=\int_{0}^{\alpha} f(\alpha)=\frac{A}{\beta} \int_{T_{0}}^{T} \exp \left(-\frac{E}{R T}\right) \mathrm{d} T .
$$

The conversion rate $\alpha$ can be calculated from TG data of thermogravimetric analysis, and the mechanism function can be selected from 47 function forms in the literature. The formulas for calculating $\alpha$ are as follows:

$$
\alpha=\frac{m_{0}-m_{t}}{m_{0}-m_{\infty}} \text {. }
$$

where $m_{0}$ is the initial mass, $m_{t}$ is the residual mass at $t$ time, and $m_{\infty}$ is the mass of the sample at the end of the reaction. The purpose of kinetic analysis is to obtain activation energy $E$, pre-exponential factor $A$, and mechanism function of the reaction process $f(\alpha)$.

\section{Results and Discussions}

3.1. TG-DSC. Figure 1 shows the TG and DTG profiles of the pyrolysis process of SJC, WJG, ZJM, and HCG coals at different heating rates. According to the TG and DTG curves, the pyrolysis process can be roughly divided into three stages. The first stage is the desorption stage, the removal of water and gas adsorbed by coal particles is 

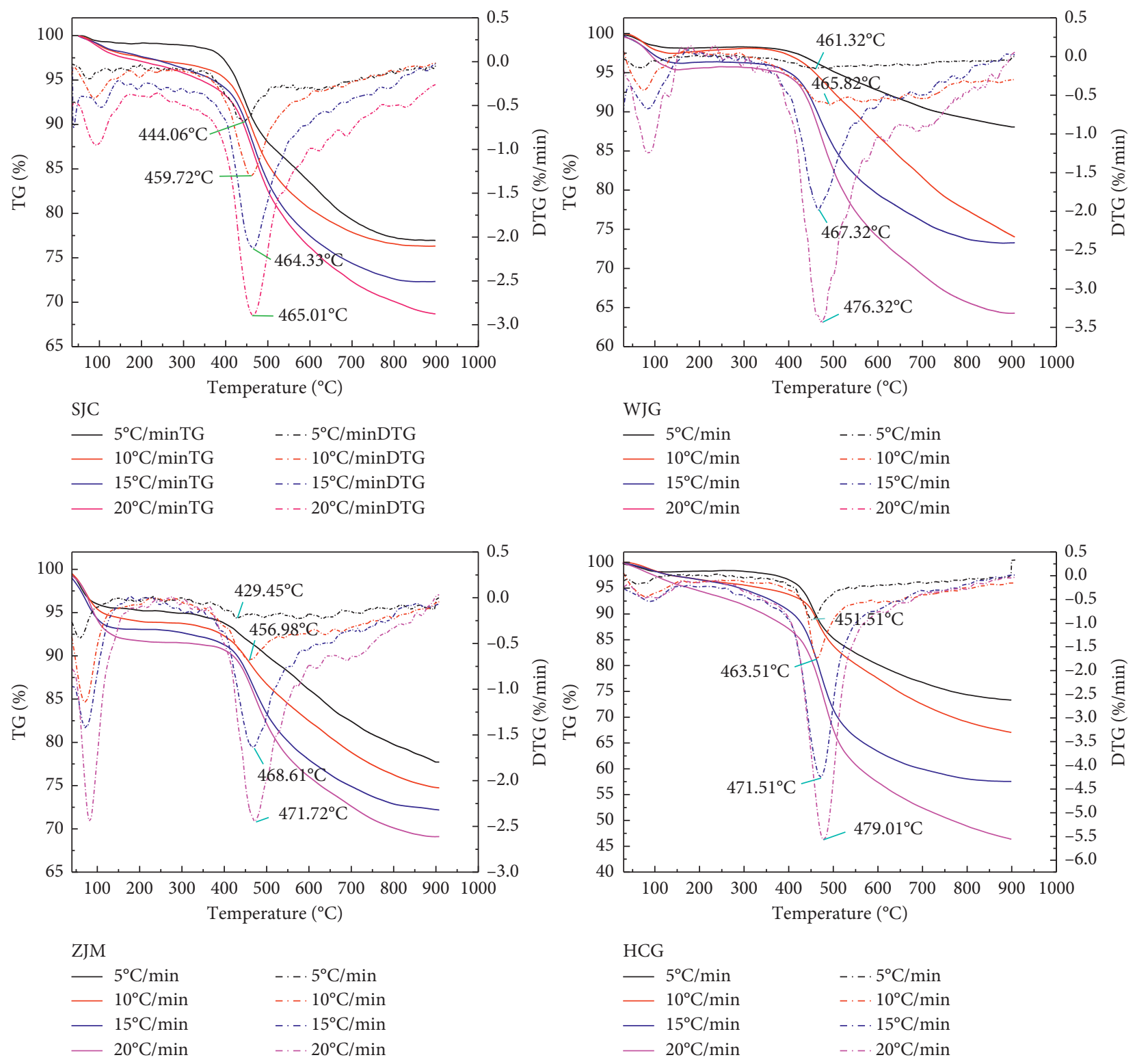

FIgure 1: The curves of TG and DTG.

usually completed before $300^{\circ} \mathrm{C}$. The second stage is the thermal decomposition process, the main weight loss stage, the unstable bridge of the coal and the weak bond generate gas, tar, and semicoke, and the temperature range is between $350 \sim 650^{\circ} \mathrm{C}$. Finally, the third stage is the polycondensation reaction between the semicoke generated in the thermal decomposition stage, releasing a small amount of gas to form coke. As the heating rate increases, the TG profile shifts to the left, and the final weight loss of the coal becomes larger, and the temperature corresponding to the peak of the DTG becomes larger. This is because the progress of the pyrolysis reactions and the escape of the products require a certain period of time. When the heating rate increases, some products cannot precipitate in time, resulting in a lag phenomenon. The DSC curve shown in Figure 2 describes the endothermic and exothermic phenomena of physical and chemical reactions during coal pyrolysis. It can be seen that the change in enthalpy of pyrolysis of different coals at different heating rates has no obvious regularity because the coal structure and pyrolysis process are quite complex, the structure and composition of different coals are different, and the pyrolysis process is also different.

3.2. Kinetic Analysis. In this paper, the kinetics of the second stage of pyrolysis, i.e., the thermal decomposition stage, which accounts for the main weight loss, is analyzed. The analytical methods adopted include the FWO method, Kissinger method, general integral method, and MacCallum-Tanner method. The specific calculation formulas are as follows. 

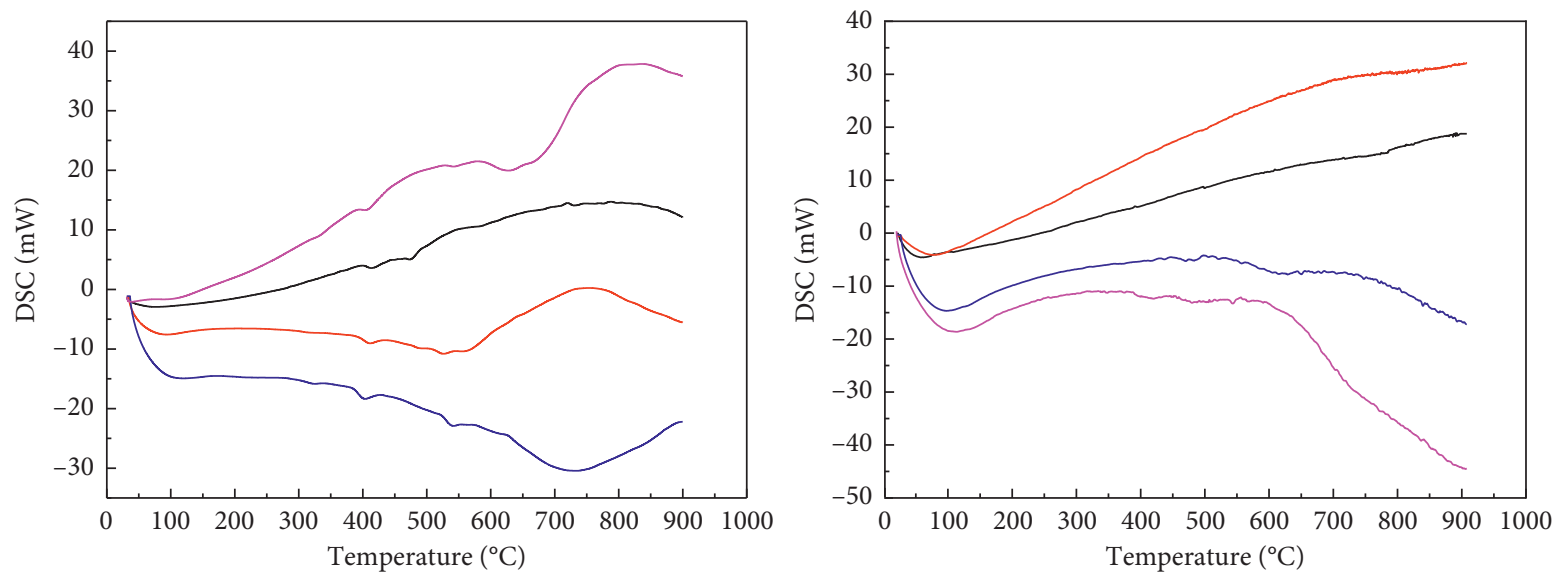

SJC

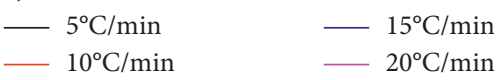

WJG
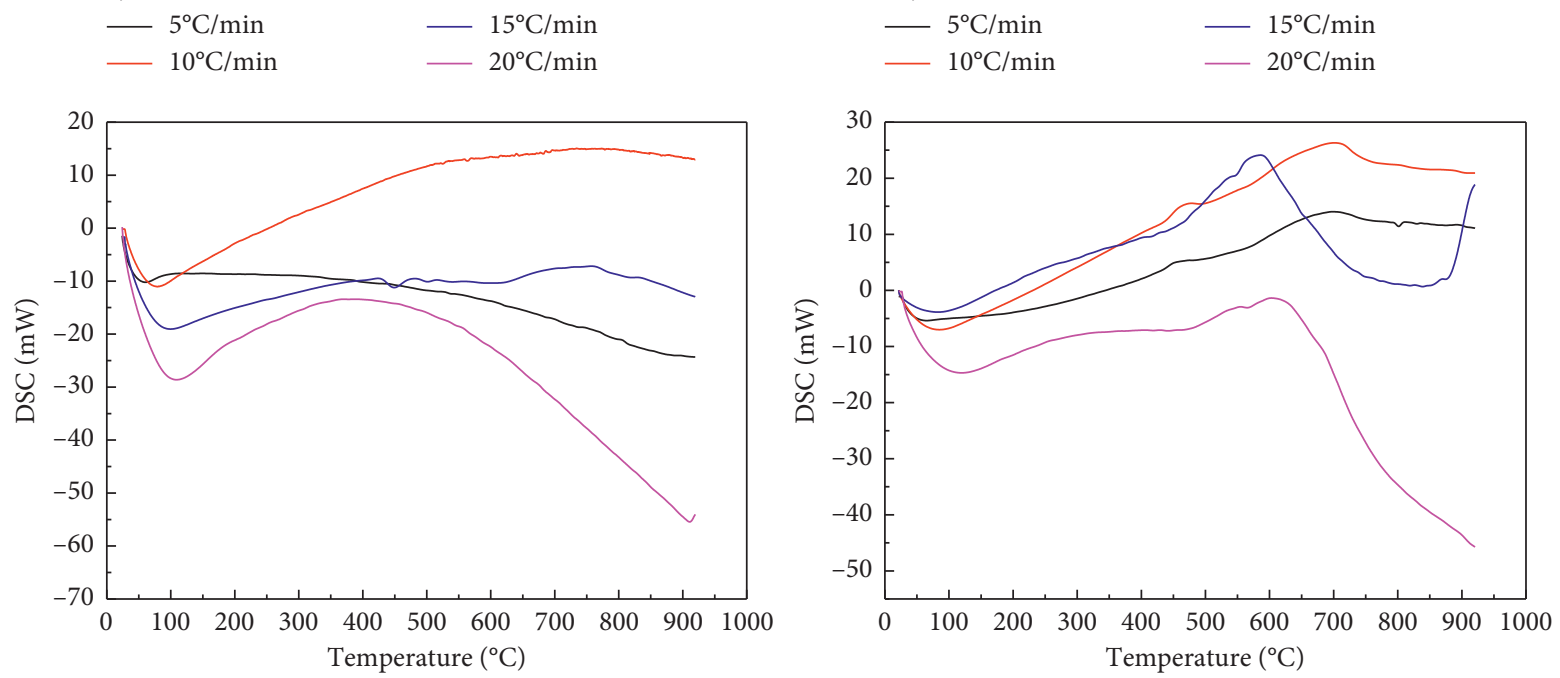

ZJM

$\begin{aligned}- & 5^{\circ} \mathrm{C} / \mathrm{min} \\ - & 10^{\circ} \mathrm{C} / \mathrm{min}\end{aligned}$

$-15^{\circ} \mathrm{C} / \mathrm{min}$

HCG

$-5^{\circ} \mathrm{C} / \mathrm{min}$

$-15^{\circ} \mathrm{C} / \mathrm{min}$

$-10^{\circ} \mathrm{C} / \mathrm{min}$

$-20^{\circ} \mathrm{C} / \mathrm{min}$

FIGURE 2: DSC profiles.

\subsubsection{FWO Method.}

$\log \beta_{i}=\log \left(\frac{A E_{\alpha}}{R G\left(\alpha_{i}\right)}\right)-2.315-0.4567 \frac{E}{R T_{i}}, \quad i=1,2,3,4$,

where $\beta_{i}$ is the heating rate, $E_{\alpha}$ is the activation energy, and $T_{i}$ is the corresponding reaction temperature on TG data. Under different heating rates, with the same conversion, $G(\alpha)$ will be a constant value. Then, $\log \beta_{i}$ versus $1 / T_{i}$ becomes a linear line so that $E$ can be calculated from the slope of the regression line.

\subsubsection{Kissinger Method.}

$$
\ln \left(\frac{\beta_{i}}{T_{p i}^{2}}\right)=\ln \frac{A_{\mathrm{K}} R}{E_{\mathrm{K}}}-\frac{E_{\mathrm{K}}}{R} \frac{1}{T_{p i}}, \quad i=1,2,3,4,
$$

where $E_{\mathrm{K}}$ is the activation energy, $A_{\mathrm{K}}$ is the pre-exponential factor, and $T_{p i}$ is the temperature corresponding to the peak on DTG. The linear regression curve of $\ln \left(\beta_{i} / T_{p i}^{2}\right)-T_{p i}$ was plotted according to the temperature corresponding to the maximum weight loss rate in four DTG data. The activation energy $E_{\mathrm{K}}$ was calculated by slope and the pre-exponential factor $A_{\mathrm{K}}$ was calculated by intercept.

3.2.3. General Integral Method. Based on the Coats-Redfern approximate expression, equation (3) is transformed into equation (7):

$$
G(\alpha)=\frac{A}{\beta} \frac{R T^{2}}{E}\left(1-\frac{2 R T}{E}\right) \exp \left(-\frac{E}{R T}\right) .
$$

In this work, equation (7) can be simplified considering $2 R T / E \ll 1$, the logarithmic form is presented as:

$$
\ln \left[\frac{G(\alpha)}{T^{2}}\right]=\ln \left(\frac{A R}{\beta E}\right)-\frac{E}{R T} \text {. }
$$


3.2.4. MacCallum-Tanner Method. When $u=E /(R T)$, equation (3) can be rewritten as

$$
G(\alpha)=\frac{A}{\beta} \int_{T_{0}}^{T} \exp \left(-\frac{E}{R T}\right) \mathrm{d} T=\frac{A E}{\beta R} \int_{E / R T}^{+\infty} \frac{e^{-u}}{u^{2}} \mathrm{~d} u=\frac{A E}{\beta R} P(u),
$$

where the function $P(u)$ is the temperature integral that has no analytic solutions. Different from the general integral, MacCallum-Tanner does not require approximation of $P(u)$. The relationship between $P(u)$ and $E$ is as follows:

$$
-\log P_{\mathrm{MT}}(u)=0.4828 E^{0.4357}+\frac{0.449+0.217 E}{0.001 T} .
$$

Thus, the MacCallum-Tanner equation can be obtained through substituting equation (10) into equation (9):

$$
\log [G(\alpha)]=\log \left(\frac{A E}{\beta R}\right)-0.4828 E^{0.4357}-\frac{0.449+0.217 E}{0.001} \frac{1}{T} .
$$

When using the general integral method and MacCallum-Tanner method, it is necessary to assume the function form of $G(\alpha)$ and to fit $\ln \left[G(\alpha) / T^{2}\right]-1 / T$ and $\ln [G(\alpha)]-1 / T$, respectively. When the correlation coefficient of fitting curve approaches 1 , it is the correct mechanism function. The three principles for determining the correct mechanism function are high linear correlation coefficient, close activation energy to that of FWO and Kissinger methods, and clear physical meaning of the mechanism function.

The data used in the FWO method, general integration method, and MacCallum-Tanner method are $\alpha-T$ of the TG profile. When calculating, firstly, the data points are collected from the TG curve and the $\alpha_{i}$ is obtained by equation (4). Then, the corresponding $T_{i}$ data of $\alpha_{i}$ in the range of $0-1.0$ are collected by the step size of 0.025 . The Kissinger method is based on four different heating rates and the temperature corresponding maximum weight loss rates. Figure 3 reveals the activation energy of four coals in the thermal decomposition stage calculated by the FWO method.

Figure 3 indicates that the activation energies of SJC, WJG, ZJM, and HCG coals during pyrolysis have been changing, with the activation energies ranging from 114.99 to $630.31 \mathrm{~kJ} / \mathrm{mol}, 80.13$ to $302.15 \mathrm{~kJ} / \mathrm{mol}, 74.32$ to $164.97 \mathrm{~kJ} / \mathrm{mol}$, and 123.51 to $404.49 \mathrm{~kJ} / \mathrm{mol}$, respectively. The variation tendency of activation energy of coal SJC can be divided into three parts: when $0<\alpha<0.150, E$ increases continuously; when $0.150<\alpha<0.800, E$ decreases steadily; and when $0.800<\alpha<1.0, E$ decreases rapidly. The change in activation energy is the manifestation of the diversification of internal reaction mechanism. Because the activation energy of the initial and termination stages of the reaction changes dramatically, it is generally considered that there is no stable mechanism function, and the whole reaction mechanism is determined by the mechanism of the dominant process [14]. Therefore, the range of the mechanism function of SJC coal thermal decomposition reaction is determined to be from 0.150 to 0.800 . The activation energies of WJG, ZJM, and HCG are similar to those of SJC and can be divided into three

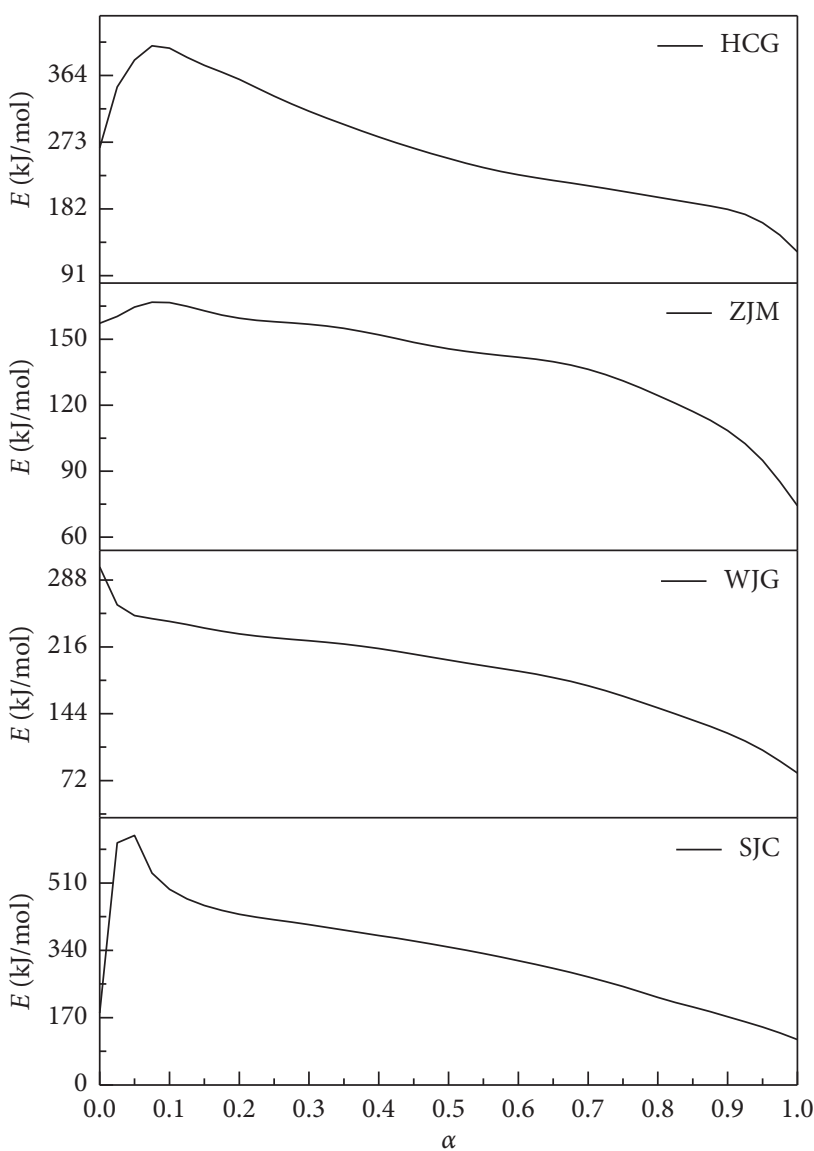

Figure 3: $E-\alpha$.

steps. Similarly, the range of mechanism functions of WJG, ZJM, and HCG coal is $0.050-0.800,0.100-0.800$, and $0.100-0.920$, respectively.

According to 47 mechanism functions in the literature, the general integration method and MacCallum-Tanner method fit $\alpha-T$ data of four coals at different heating rates in the light of equations (5) and (8) respectively, and determine the correct mechanism function of coal thermal decomposition reaction according to three principles. The results show that the most probable mechanism function of thermal decomposition reaction of coal SJC, coal HCG, and coal ZJM is function No.37, and the most probable mechanism function of coal WJG is function No.17. The differential form, integral form, and physical meaning of the most probable mechanism function are shown in Table 2. The kinetic parameters of the thermal decomposition stage for all coals calculated by four algorithms are shown in Tables 3-6. In these calculations, except for the poor linear correlation coefficients calculated by the Kissinger method for SJC, the Kissinger method for WJG, and the FWO method for ZJM (correlation coefficients are $0.9689,0.9700$, and 0.9751 , respectively), the other correlation coefficients are all above 0.98 , the overall fitting accuracy is high, and the kinetic calculation results are reliable.

The calculated results show that the kinetic parameters of four coals obtained by two kinds of the model-free method 
TABle 2: The differential form and integral form of mechanism function.

\begin{tabular}{lccccc}
\hline Coal & Number & Function name & $f(\alpha)$ & $G(\alpha)$ & Function mechanism \\
\hline SJC & 37 & Reaction series & $(1-\alpha)^{2}$ & $(1-\alpha)^{-1}-1$ & Chemical reaction \\
WJG & 17 & Avrami-Erofeev & $(2 / 3)(1-\alpha)[-\ln (1-\alpha)]^{-(1 / 2)}$ & {$[-\ln (1-\alpha)]^{3 / 2}$} & Randomly nucleating and nucleus growth \\
HCG & 37 & Reaction series & $(1-\alpha)^{2}$ & $(1-\alpha)^{-1}-1$ & Chemical reaction \\
ZJM & 37 & Reaction series & $(1-\alpha)^{2}$ & $(1-\alpha)^{-1}-1$ & Chemical reaction \\
\hline
\end{tabular}

TABLE 3: Calculation results of coal SJC.

\begin{tabular}{|c|c|c|c|c|}
\hline Method & $\beta\left({ }^{\circ} \mathrm{C} / \mathrm{min}\right)$ & $E(\mathrm{~kJ} / \mathrm{mol})$ & $A(1 / S)$ & $R^{2}$ \\
\hline \multirow{4}{*}{ The general integral } & 5 & 223.657 & $1.16 \times 10^{14}$ & 0.9997 \\
\hline & 10 & 160.223 & $9.85 \times 10^{8}$ & 0.9985 \\
\hline & 15 & 163.37 & $1.65 \times 10^{9}$ & 0.9984 \\
\hline & 20 & 153.127 & $5.09 \times 10^{8}$ & 0.9956 \\
\hline \multirow{4}{*}{ MacCallum-Tanner } & 5 & 228.401 & $3.13 \times 10^{14}$ & 0.9997 \\
\hline & 10 & 165.168 & $2.41 \times 10^{9}$ & 0.9998 \\
\hline & 15 & 168.254 & $4.04 \times 10^{9}$ & 0.9986 \\
\hline & 20 & 158.027 & $1.22 \times 10^{9}$ & 0.9963 \\
\hline \multirow{3}{*}{$\begin{array}{l}\text { Kissinger } \\
\text { FWO }\end{array}$} & & 177.53 & $2.75 \times 10^{10}$ & 0.9983 \\
\hline & - & 247.84 & $5.19 \times 10^{15}$ & 0.9689 \\
\hline & - & 329.526 & - & 0.9856 \\
\hline
\end{tabular}

TABLE 4: Calculation results of coal WJG.

\begin{tabular}{|c|c|c|c|c|}
\hline Method & $\beta\left({ }^{\circ} \mathrm{C} / \mathrm{min}\right)$ & $E(\mathrm{~kJ} / \mathrm{mol})$ & $A(1 / S)$ & $R^{2}$ \\
\hline \multirow{4}{*}{ The general integral } & 5 & 217.04 & $9.55 \times 10^{12}$ & 0.9940 \\
\hline & 10 & 207.72 & $1.78 \times 10^{12}$ & 0.9960 \\
\hline & 15 & 187.76 & $6.92 \times 10^{10}$ & 0.9919 \\
\hline & 20 & 187.23 & $6.03 \times 10^{10}$ & 0.9874 \\
\hline \multirow{4}{*}{ MacCallum-Tanner } & 5 & 221.86 & $2.57 \times 10^{13}$ & 0.9947 \\
\hline & 10 & 212.71 & $4.79 \times 10^{12}$ & 0.9965 \\
\hline & 15 & 192.74 & $1.78 \times 10^{11}$ & 0.9930 \\
\hline & 20 & 192.35 & $1.62 \times 10^{11}$ & 0.9891 \\
\hline \multirow{3}{*}{$\begin{array}{l}\text { Kissinger } \\
\text { FWO }\end{array}$} & & 200.34 & $8.51 \times 10^{11}$ & 0.9928 \\
\hline & - & 203.05 & $5.99 \times 10^{11}$ & 0.9700 \\
\hline & - & 192.83 & - & 0.9920 \\
\hline
\end{tabular}

TABLE 5: Calculation results of coal ZJM.

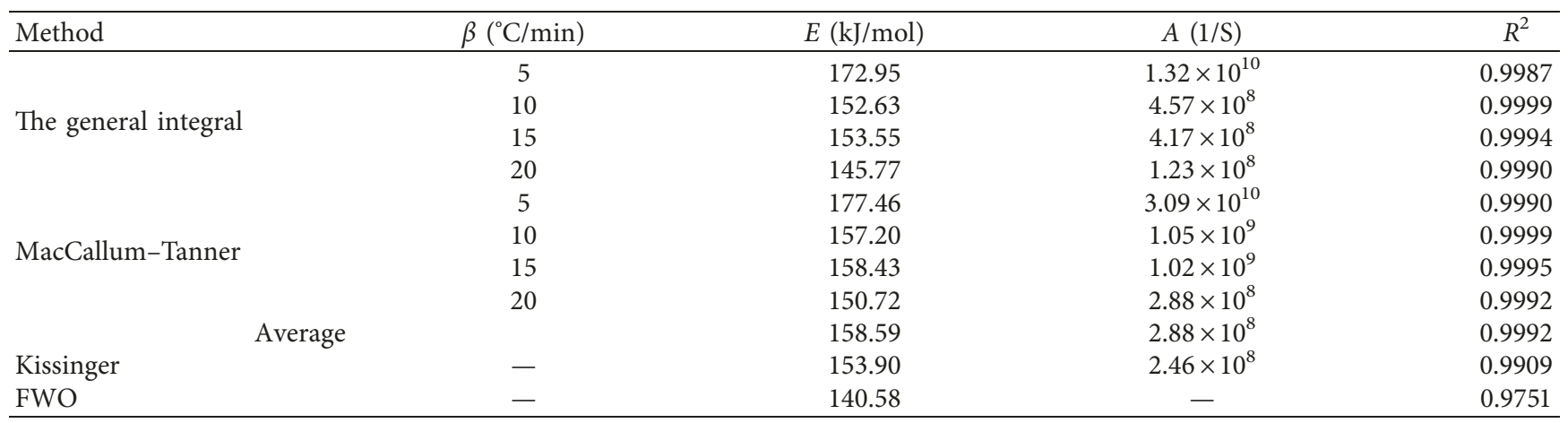

are different, and the order of activation energy is $\mathrm{ZJM}<\mathrm{WJG}<\mathrm{HCG}<\mathrm{SJC}$. This is due to the different structure and composition of different coals and the different reactions during pyrolysis. The average activation energies of coals SCC, WJG, ZJM, and HCG calculated by model-fitting methods are $177.53 \mathrm{~kJ} / \mathrm{mol}, 200.34 \mathrm{~kJ} / \mathrm{mol}, 158.59 \mathrm{~kJ} / \mathrm{mol}$, and $240.47 \mathrm{~kJ} / \mathrm{mol}$, respectively. Coals SJC, HCG, and ZJM conform to the reaction series equation. The rates of thermal decomposition reaction are controlled by chemical reaction, but their coefficients and exponents of the specific mechanism function expression are different. Coal WJG conforms to the Avrami-Erofeev equation. The expressions of average activation energy, pre-exponential factor, and reaction mechanism function of different coals are substituted into 
TABLE 6: Calculation results of coal HCG.

\begin{tabular}{|c|c|c|c|c|}
\hline Method & $\beta\left({ }^{\circ} \mathrm{C} / \mathrm{min}\right)$ & $E(\mathrm{~kJ} / \mathrm{mol})$ & $A(1 / \mathrm{S})$ & $R^{2}$ \\
\hline \multirow{4}{*}{ The general integral } & 5 & 276.67 & $3.98 \times 10^{17}$ & 0.9995 \\
\hline & 10 & 252.23 & $5.13 \times 10^{15}$ & 0.9997 \\
\hline & 15 & 211.63 & $8.71 \times 10^{12}$ & 0.9991 \\
\hline & 20 & 210.43 & $6.76 \times 10^{12}$ & 0.9998 \\
\hline \multirow{4}{*}{ MacCallum-Tanner } & 5 & 282.17 & $1.41 \times 10^{18}$ & 0.9996 \\
\hline & 10 & 257.84 & $1.70 \times 10^{16}$ & 0.9997 \\
\hline & 15 & 216.94 & $2.51 \times 10^{13}$ & 0.9992 \\
\hline & 20 & 215.86 & $1.95 \times 10^{13}$ & 0.9998 \\
\hline \multirow{3}{*}{$\begin{array}{l}\text { Kissinger } \\
\text { FWO }\end{array}$} & & 240.47 & $1.05 \times 10^{15}$ & 0.9995 \\
\hline & - & 223.67 & $1.53 \times 10^{13}$ & 0.9976 \\
\hline & - & 264.33 & - & 0.9900 \\
\hline
\end{tabular}

equation (2), respectively, and the kinetic equations of their thermal decomposition reactions are obtained. Through the corresponding kinetic equation, the thermal decomposition reaction process of the same kind of coal can be simulated at any heating rate.

\section{Conclusion}

(1) The pyrolysis process of four coals in northern Shaanxi can be divided into three stages: desorption stage, thermal decomposition stage, and polycondensation reaction stage. With the increase in heating rate, the temperature corresponding to the maximum devolatilization rate increases and the final devolatilization of coal increases.

(2) The most probable mechanism function of coal SJC, ZJM, and HCG in the thermal decomposition reaction stage is No. 37. The reaction rate is controlled by chemical reaction. The most probable mechanism function of coal WJG is No. 17. The function mechanism is random nucleation and subsequent growth. The activation energies of coals SJC, WJG, ZJM, and HCG are $177.53 \mathrm{~kJ} / \mathrm{mol}, 200.34 \mathrm{~kJ} / \mathrm{mol}$, $158.59 \mathrm{~kJ} / \mathrm{mol}$, and $240.47 \mathrm{~kJ} / \mathrm{mol}$, respectively.

\section{Data Availability}

The data used to support the findings of this study are included within the supplementary information files.

\section{Conflicts of Interest}

The authors declare that they have no conflicts of interest.

\section{Acknowledgments}

This work was supported by the National Natural Science Foundation of China (no. 21663034).

\section{Supplementary Materials}

The data in the supplementary file contain all the basic data in this article. (Supplementary Materials)

\section{References}

[1] China National Administration of Coal Geology, Occurrence Law and Resource Evaluation of Coal Resources in China, Beijing: Science Press, Beijing, China, 2016, in Chinese.

[2] K. Xie, Research on the Development Strategy of Energy "Golden Triangle", Chemical Industry Press, Beijing, China, 2016, in Chinese.

[3] H. R. Zhang, S. Li, K. E. Kelly, and E. G. Eddings, "Underground in situ coal thermal treatment for synthetic fuels production," Progress in Energy and Combustion Science, vol. 62, pp. 1-32, 2017.

[4] S. Li, B. Yang, F. Xiuyan et al., "Experimental study of typical Shanbei long flame coals pyrolysis kintics," Journal of Dalian University of Technology, vol. 53, no. 3, pp. 333-339, 2013, in Chinese.

[5] B. de Caprariis, P. De Filippis, C. Herce, N. Verdone et al., "Double-Gaussian distributed activation energy model for coal devolatilization," Energy \& Fuels, vol. 26, no. 10, pp. 6153-6159, 2012.

[6] J. Wang, L. Peng, L. Liang et al., "Kinetics modeling of lowrank coal pyrolysis based on a three-gaussian distributed activation energy model (DAEM) reaction mode," Energy \& Fuels, vol. 30, no. 11, pp. 9693-9702, 2016.

[7] H. Song, G. Liu, J. Zhang, and J. Wu, "Pyrolysis characteristics and kinetics of low rank coals by TG-FTIR method," Fuel Processing Technology, vol. 156, pp. 454-460, 2017.

[8] S. Shi, P. Ma, F. Fan et al., "Investigation on combustion characteristics and kinetics of bamboo hydrochar," Acta Energyiae Solaris Sinica, vol. 39, no. 9, pp. 2648-2655, 2018, in Chinese.

[9] C. Wang, S. Wang, S. Zhang et al., "Pyrolysis kinetics of bamboo PulpFiber reinforced epoxy resin composites treated by nano particles," Journal of Building Materials, vol. 21, no. 2, 2018, in Chinese.

[10] L. Peng, Y. Zhang, W. Jiang, A. Wei, T. Liu, and J. Wu, "Simulation study of shenmu coal pyrolysis by gas heat carrier based on a moving bed," Energy \& Fuels, vol. 29, no. 11, 2015.

[11] A. A. Jain, A. Mehra, and V. V. Ranade, "Processing of TGA data: analysis of isoconversional and model fitting methods," Fuel, vol. 165, pp. 490-498, 2016.

[12] J. Liu, J. Ma, L. Luo, H. Zhang, and X. Jiang, "Pyrolysis of superfine pulverized coal. Part 5. Thermogravimetric analysis," Energy Conversion and Management, vol. 154, pp. 491-502, 2017.

[13] R. Hu and Q. Shi, Thermal Analysis Kinetics, Science Press, Beijing, China, 2008, in Chinese.

[14] J. Shaowu, A. Yang, Y. Chen et al., "Comparative study on kinetics of dehydration reaction of pure gypsum and phosphogypsum," PTCA Part B Chemical Analysis, vol. 51, no. 10, pp. 1373-1377, 2015, in Chinese. 

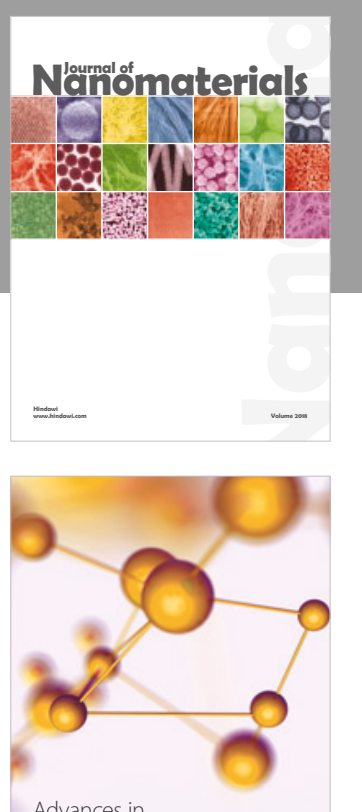

Physical Chemistry
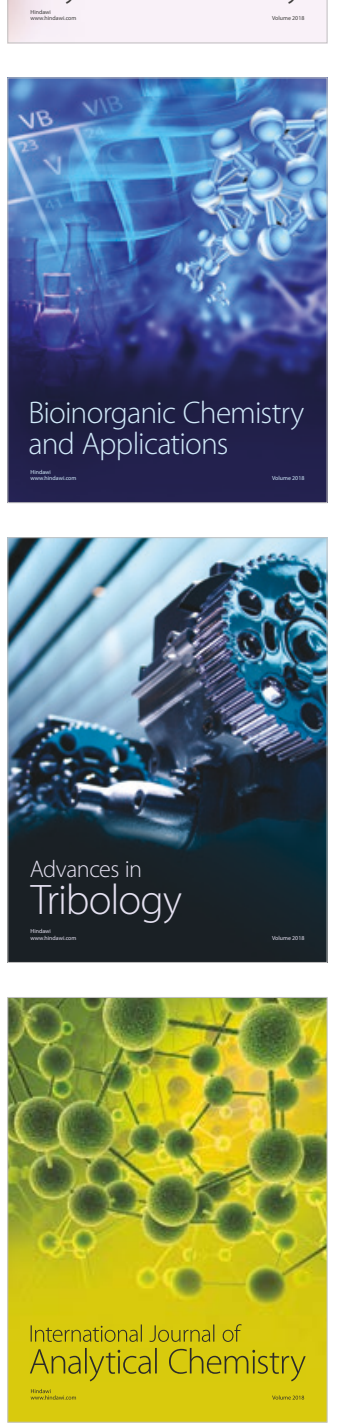

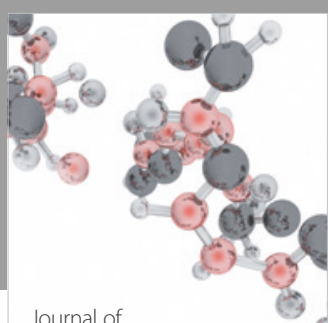

Analytical Methods

in Chemistry

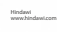

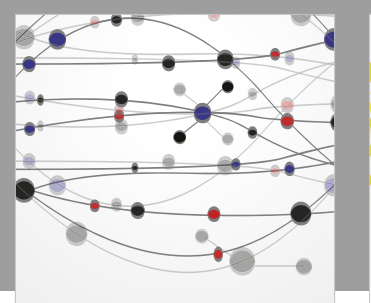

The Scientific World Journal

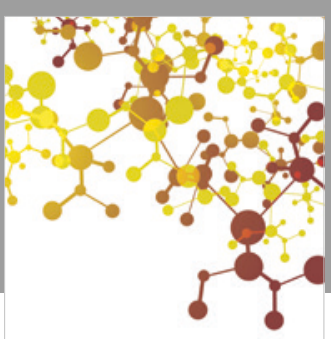

Journal of

Applied Chemistry
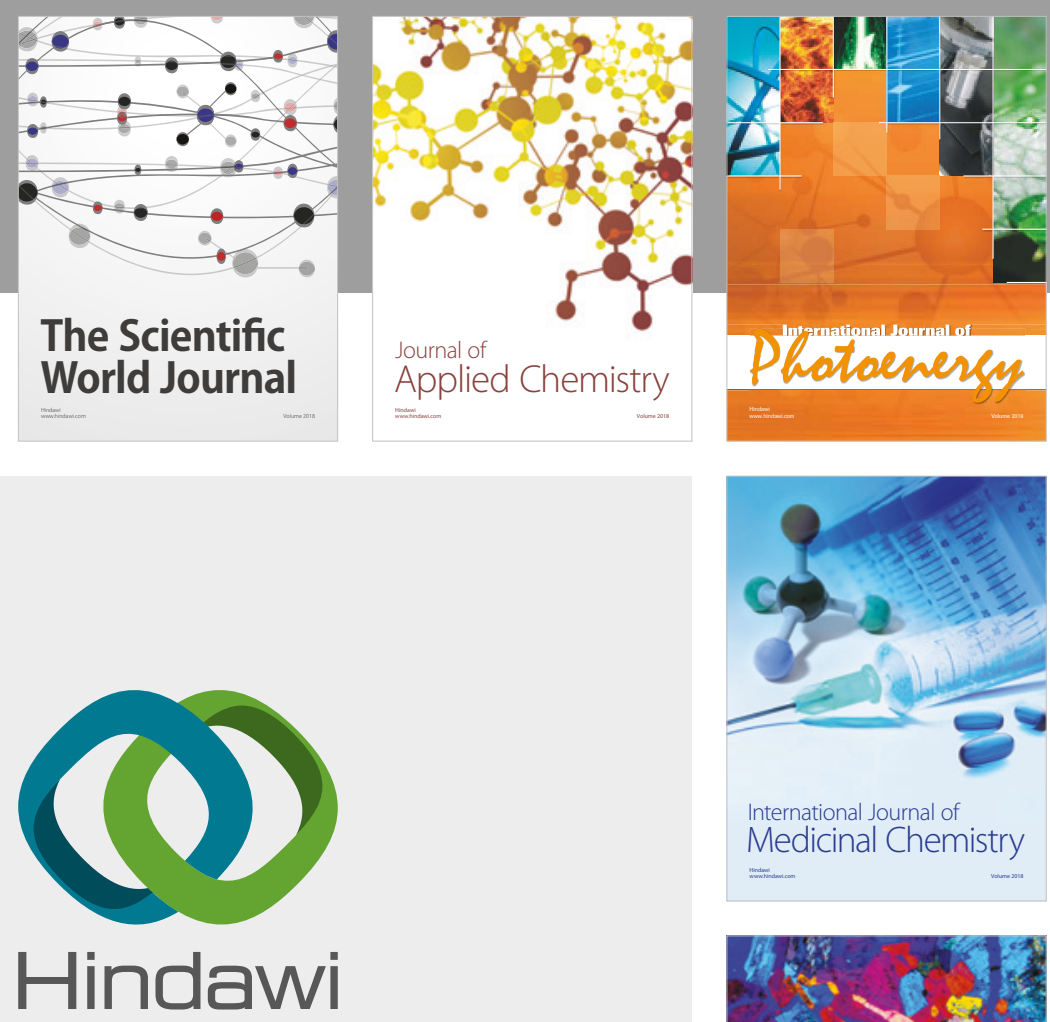

Submit your manuscripts at

www.hindawi.com
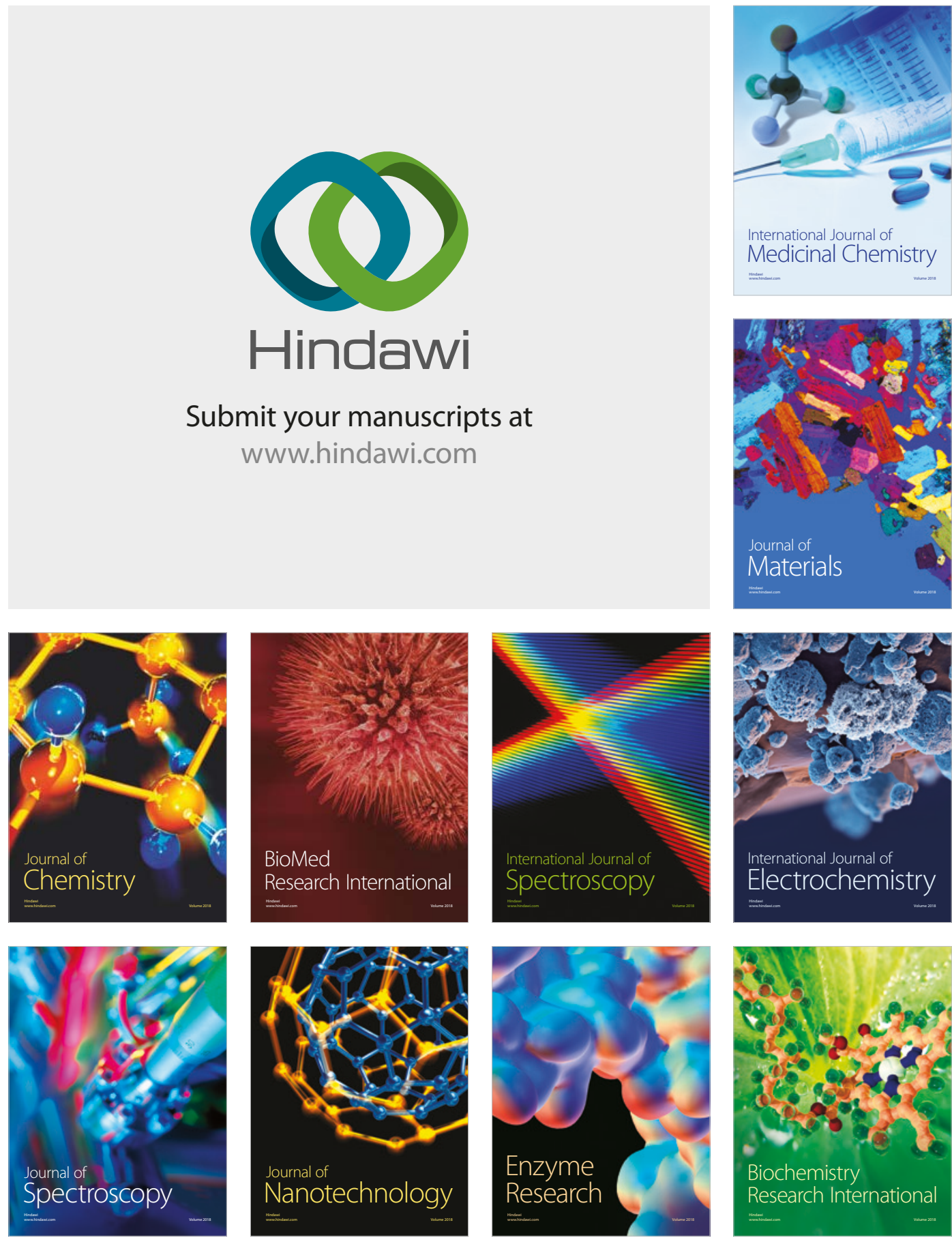
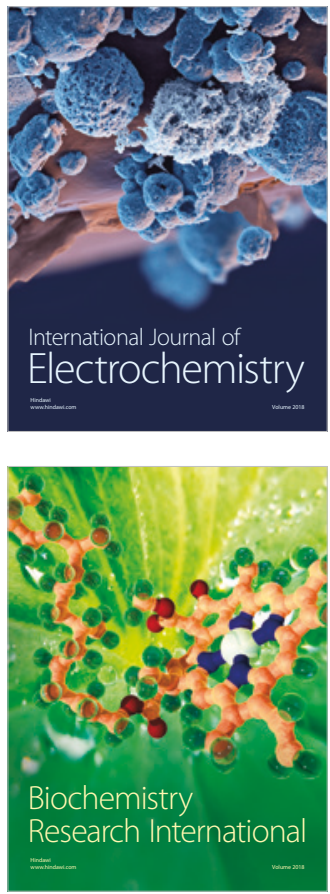